\title{
The Norwegian 22 July 2011 Terror Acts and Mass Murder: Insanity, Evilness or Both?
}

\author{
Henning Værøy* \\ Department for Research and Development, Division of Mental Health Services, Akershus University Hospital, \\ Lørenskog, Norway \\ Email: $\underline{\text { Heve@ahus.no }}$
}

Received 5 July 2014; revised 6 August 2014; accepted 2 September 2014

Copyright (C) 2014 by author and Scientific Research Publishing Inc.

This work is licensed under the Creative Commons Attribution International License (CC BY). http://creativecommons.org/licenses/by/4.0/

c) (7) Open Access

\begin{abstract}
This review presents unique information rarely seen in a description of a politically extreme right wing terrorist. During the trial following the terror acts in Norway on July $22^{\text {nd } 2011}$, the author, a forensic psychiatrist was at the time engaged by a national Norwegian newspaper to comment on the court proceedings. The author has later thoroughly gone through all available background material such as the terrorist's childhood, relationship to his mother, childhood psychological evaluation, the interviews made by the forensic psychiatrists and information from the police documents. This information is shared in the review. The author also discusses how it was possible for two pairs of court appointed experienced forensic psychiatrists to arrive at completely different conclusions. One pair concluded with insanity due to Paranoid Schizophrenia and the second pair found no signs of psychotic disorder at all and concluded with Narcissistic Personality Disorder. The court found the terrorist capable to stand trial and sentenced him to 21 years in preventive detention with 10 years to be served before the possibility to apply for an appeal.
\end{abstract}

\section{Keywords}

Terrorism, Insanity, Forensic Diagnosis, Mental Disorders, Personality

\section{The 22 July Terror Acts: Background and Consequences}

Norway was struck by an outrageous act of terrorism on 22 July 2011. First, the centre of Oslo, including government buildings, was hit by a car bomb, and later a terrorist executed young members of the labour party's youth organisation at an island camp outside Oslo. Within 189 minutes [1], 77 persons lost their lives. Several survived, but had been marked for life.

*MD, Dr. in Medical Sciences (Ph.D.), Specialist in Psychiatry. 
The court engaged two forensic psychiatrists (FP-1) who, after examining the murderer, concluded that he was suffering from insanity due to paranoid schizophrenia as defined by the World Health Organization International Classification of Diseases Version 10 (ICD 10) criteria [2].

Norway is familiar to a certain extent with events involving dangerous psychiatric patients and inadequate hospital security measures. In the past, there have been cases in which psychiatric healthcare treatment programs have not managed to treat and follow up the most dangerous psychiatric patients adequately. The collaboration between psychiatry and the legal system has, in some cases, failed badly in protecting the general population from such severely ill patients. A growing distrust in psychiatric health care is emerging in Norway, and after the insanity conclusion was presented by FP-1 in the Anders Behring Breivik [ABB] case, this frustration and distrust were further encouraged. A public debate on psychiatry's actual role in forensic settings and current practice has followed. During the debate, the court decided to appoint two additional forensic psychiatrists [FP-2] who concluded that the murderer had no signs of insanity or psychosis, but was a political extremist suffering from narcissistic personality disorder [NPD] and traits of antisocial personality disorder [APD]. A recent paper reported on how these issues were handled by the court in the verdict [3].

\section{The Terrorist Anders Behring Breivik}

\subsection{Childhood}

In 1981, ABB's mother [4] applied for childcare assistance for her two children, but especially for her son, who was about 2 years old. After separating from her husband in 1980, she was exhausted having to raise the two children as a single parent. The boy was described as very challenging, and a resource family where the children lived during weekends was offered. Later, for a period during 1983 and 1984, the mother once more asked for assistance because she felt that her now 4-year-old son was hyperactive, passive and clingy [5]. The family of three was admitted to the family department of a children's psychiatric hospital for about three weeks, at the end of which a psychologist recommended that custody of the 4-year-old boy should be taken away from his mother. It was argued that the boy was in need of a foster home because he had become contact avoiding, anxious and passive, but with evident restlessness. The child had also developed strategies for getting out of difficult situations, e.g. what was described as a self-imposed avoidant smile [5]. The psychologist also reported that the boy had difficulties with expressing himself emotionally, and that he was passive when playing with others. Despite maintaining some elements of pleasure and joy, he had an almost total lack of spontaneity [5].

During court proceedings in the spring of 1983, the father asked the court to grant him custody of the children. This was based on advice he had received from the family department of the children's psychiatric hospital who stated that unchanged, continued care provided by the mother would most likely increase the boy's risk of developing "serious psychopathology" [6]. In contrast to this, the local public childcare employees basically found nothing wrong with the mother and her two infants. The father lost his case and no longer pursued his claims.

From the forensic report written by FP-2 [7], it is known that ABB visited his father in the south of France for three weeks every summer for some years. He was under crossfire from his parents, being constantly reminded by his mother that his father was an avaricious "criminal" and by his father that his mother was "the crazy one". The report [7] also mentions that the mother had several boyfriends during ABB's upbringing. Two of these became stable father figures, from whom ABB sought support.

Some of the detailed information about the relationship between mother and son in 1983 was initially presented during the 2012 court proceedings. Later, the court prevented publication of this information in the media on the grounds of the mother's right to privacy. What is known from the present author's personal notes from the proceedings is that a psychologist found reason to suspect that the mother transferred her sexual frustrations onto the boy.

ABB also confirmed that he once bought a cake and a dildo as a birthday gift for his mother after her relationship with one of her lovers had ended. Unconfirmed information from ABB's contact with a foster home states that $\mathrm{ABB}$ had been encouraged by his mother to touch the foster father's penis in order to observe how it reacted. According to the foster parents, this emerged after a statement from his sister claiming that she had been encouraged to do the same by her father.

\subsection{The Mother and Son Relationship}

In a recently published book [8], the author chose to publish some previously censored information. In brief, 
ABB's mother had been admitted into psychiatric care several times due to problems related to emotional instability and later paranoid delusions and hallucinations. She originally wanted an abortion when she became pregnant with $\mathrm{ABB}$, but failed to submit an application before the legal limit. During the pregnancy, she felt that the unborn child was a difficult foetus due to its general activity, especially its kicking. The latter was perceived as being something the foetus almost did on purpose. She stopped breastfeeding him after 10 months because she could not bear his aggressive sucking which she perceived and consequently described as something destructive. According to the mother, as ABB grew up he became more and more demanding. Other terms used by her were that her son was "hyperactive and clingy".

When ABB was 2 years old, she expressed her fears of what he might do, especially to his sister. The children's psychiatric hospital wrote that they considered her incapable of meeting her son's needs for clarity and structure. The 2-year-old's response to his mother's ambivalence was described as being a devious smile and sometimes laughter. She explained that when she slapped him he always responded by saying that "It didn't hurt, it didn't hurt”. Also, the staff at the kindergarten observed that ABB did not cry. Nor did he show other signs of pain when expected, e.g. after a fall. The mother expressed that she wanted "to peel him off me" and that she had a death wish in his regard.

How much the 2 - 3 years old perceived of his mother's thoughts and ideas is impossible to know. After being captured following the terror acts ABB said that "it would have been better if my father and his new wife had won the custody case", referring to the court's ruling when he was around 4 years old. He also made statements like "My mother is not intellectually capable...", "Women don't understand the concept of honour" and " $90 \%$ of them are emotionally unstable". Likewise, "Fathers should automatically be granted custody of children because those who control the cradle control the world".

The children's psychiatric hospital also wrote that ABB was a victim of his mother's aggressive paranoid projections and fear of sexual intimacy with men in general. Furthermore, as part of the communication between mother and child observed, the hospital described how they lived in a physical symbiosis - as if mother and son were united in one body. "After they were left on their own, Anders for some time slept in his mother's bed with close body contact" [8]. There is no concrete evidence of an incestuous relationship between mother and son, but the hospital refers to an episode in which the mother, in a somewhat "rejectful" manner, allegedly told her son to go and have sexual activity with a person outside the family. In this regard, the link between sexual abuse and the potential development of a pathological personality has been established and described [9].

ABB's mother visited her son in prison before she died in 2013. He was not allowed to attend her funeral.

\subsection{Adolescence}

The contact between father and son ended in 1995 when ABB was around 15 - 16 years old. In the same period, he was caught twice spraying and tagging trains in Oslo. The police closed the cases and no charges were made.

A police file from 1994 states that ABB did not admit any guilt but agreed to assist in removing the graffiti.

The childcare authorities also opened an investigation, but it was closed shortly after and filed as "nothing further to pursue". School reports [7] state that a teacher described ABB as a person who defended himself intensively and somewhat out of proportion, when, for example, he was late for class. The same teacher associated ABB's behaviour with the reactions of someone living with an almost irrational and constant fear.

ABB performed reasonably well at school. During the court proceedings, friends from school described ABB as an intelligent and physically stronger man than his classmates. He was also the one who helped those who were being bullied [10]. In ABB's mind, looking good was equal to looking strong. At one point, he started weight training and enhanced his progress by using steroids [11].

ABB went to high school from 1995 to 1998 but did not graduate. According to a friend interviewed by FP-2 [7], ABB left high school to start his own business. He had told his friend that he wanted to change other peoples' impression of him and that he wanted to be different from the average student. ABB had also explained that to achieve this, economic success was a major criterion. ABB had a reputation as a person not to start an argument with, but his friend knew of no situations where ABB had actually been violent.

ABB became politically active on the right wing during the high school period and he used to speak about multiculturalism and incompatibility between the Islamic world and Christianity. ABB considered Islam a political ideology and not a religion [7].

ABB claims to have been mentally sane during adolescence, but friends questioned some of his reactions and behaviour. There is no information available to shed light on his psychiatric health during adolescence. 
Having heard all witnesses in court, the overall impression is that ABB interacted with only very few close friends during adolescence and that he was happy to be on his own, sometimes for what some people would describe as long periods, without being more specific. However, there is also evidence that he shared apartments with friends for some periods.

There is no known history of stable girlfriends or partners. In court, some of ABB's friends disclosed their thoughts about how ABB could have lied about intimate relations to try to build an image of being the ladies' preferred choice. There are also unconfirmed rumours about sporadic contact with transsexuals.

\subsection{Adulthood}

At the beginning of his twenties, ABB underwent cosmetic surgery on his mandible, nose and forehead. According to witnesses in court, the results gave him satisfaction [12]. One friend told FP-2 [7] that ABB, at the age of around 25 - 26 years, used anabolic steroids and that he was interested in body building. The same friend mentioned that $\mathrm{ABB}$ was more aggressive in that period and that he occasionally smoked cannabis.

During the court proceedings, friends and colleagues explained that ABB had had several businesses, some profitable and others not. Common to most of his business was that they were short-lived and were associated with problems following Norwegian laws and regulations. Among his most notorious activities was a company providing falsified certificates and diplomas. This company was shut down in 2006, after which ABB lived on his savings. To make his savings last longer, he reduced his expenses by moving back to his old room at his mother's apartment.

Friends were asked in court about when ABB decided to move back in with his mother. One of them explained [7] that friends had recommended to ABB's mother not to let him move back in with her, arguing that it was the opposite of doing him a favour. ABB's argument at the time was that after having worked a lot he needed time off to do what he wanted. To ABB, this was not an illegitimate claim but in general no different from other peoples' reasons for taking extended leave. ABB had shared some reflections regarding his childhood alone with his mother who had not managed to take proper care of him during his upbringing, referring especially to the lack of guidance. He had also explained to his friend that children in general needed a stricter upbringing that he had [7].

Of special interest during the court proceedings was the question about the existence of an organisation called the Knights Templar (KT), an ultra-right wing criminal organisation with around 7 founding members. The police had found no proof of its existence but ABB kept insisting that KT was an organisation of which he was a founding member. Also of interest was the question of when ABB started to write his manifesto published just hours before the terror acts and when he started to plan and prepare for the terror acts. The truth may never be known. Still, there is enough evidence to conclude that since 2006 ABB had already made extensive preparations of which precautions to avoid being caught were an important part. As for psychiatric health issues, there is no information about any disorders or problems except for his mother's concerns that he stayed in and played World of Warcraft for days on end.

\subsection{Political Activity and Hobbies}

ABB joined the ultra-right wing party's Fremskrittspartiet [Fp] youth organisation [FpU] in 1997. There, he expressed strong opinions about immigration, but he was never considered to be a potential terrorist or a mass murderer. ABB later complained critically that the Fp had become too liberal and too busy with being accepted as politically correct in recent years. It is also known that he joined a shooting club in Oslo, which enabled him to acquire weapons legally. ABB had no official military training. All he knew about weapons was based on information from the internet, from his experience at the shooting club, and from firing guns in isolated places out in the wild. During the court proceedings, ABB explained how he prepared for the terror attacks, e.g. by renting an isolated farm, registering as a farmer in order to buy large amounts of nitrogen-based fertilizer, and how he used specific computer-based instruction programs for firearm practice and training on precision aiming. After his arrest, he cynically claimed that these latter mentioned computer programs had been most useful later, during the assassination of the summer camp participants at Utøya.

\section{Diagnostic Approach}

Guidance for the forensic psychiatric examination is given by the court. The examination by the appointed psy- 
chiatrists is based on psychiatric interviews and use of diagnostic criteria and psychometric tools like SCID II. In this case the four appointed individual psychiatrists, although operating in pairs should make separate interviews and arrive at independent conclusions. FP-1 made 13 observations [36 hours] together referring to safety measures as the main reason for why the observations were not made independently. Their approach was publicly criticized by colleagues in open court. The second pair of appointed forensic psychiatrists made their observations separately. The report made by FP-1 offers the psychiatrists' statements and conclusions. It offers very little to quote from the interviews with the terrorist compared to the report from FP-2. Since one purpose with this paper was to present a more detailed picture of $\mathrm{ABB}$, direct information from the interviews are crucial; which is why the report from FP-2 was chosen as main source.

\subsection{The Forensic Evaluations}

The police's interviews and interrogations of the perpetrator: The forensic psychiatrists' interpretations.

From the FP-2 forensic psychiatrists' report several interviews were made with the terrorist. From these, parts of the dialogue have been transcribed and added to the forensic report. Selected sequences have been translated and are presented below.

From a section of an interview:

The forensic psychiatrist (FP-2): "I want to inform you that we have not read the first psychiatric report".

The terrorist $(A B B)$ : "I am quite impressed that you have been able to control yourself in this regard. My impression is that every psychiatrist in Norway has made their comments, because it must be very tempting to do so in view of the fact that this is such an important case, so-it is impressive indeed".

Talking about the report made by FP-1 [4], ABB said: "My impression was that they specifically selected those sources that describe me in the most negative way. Their work was to a large extent based on the technique of "cut and paste". My impression, based on reading their report, is that they already at an early stage decided upon what should be the outcome and conclusion. Then they built their case supporting that decision. That is my impression after reading it...”

One of the psychiatrists in FP-2 [7] describes a sequence during an interview with ABB. Parts of this are quoted below.

FP-2: "The media claimed that you presented yourself differently in court when I was present..."

$A B B$ : "I did not think about that at all. I was myself in every way. If you had known me, then you could have foreseen that my presence at the court proceedings would have a great resemblance to a performance. Whatever I say is just a formality. My audience is a small group of persons, a few thousand in Europe, but there may be more. I am aware that this represents a reality which is too strange for most people. But it is a show... I play my part. So, if I say that I expect to receive the war cross with three swords, then, of course I know that I never will get it. And, when I say that I expect to be released immediately, I know that this is not realistic. I am just carrying through what I had planned for a long time”.

The terrorist's statements on how he is on a mission to save Norway and Europe from islamisation and how he considers the Marxist Norwegian government as being responsible for ongoing islamisation in Norway is the background for the following.

FP-2: "But why not just be yourself?"

$A B B$ : "In a way I am myself because I present a completely different view on the world, a view which has not been expressed since World War II. This view is of course known in Japan and South Korea. Much of the ideology I represent is normal in Japan and South Korea. It is all about culture and related politics, but to people living in a Marxist society, my ideology seems as strange as it possibly can be”.

FP-2: "We will not go into this further, but what you claim to be a Marxist society is in fact a social democracy, or at least most people see it this way, don't they?"

$A B B$ : "I can of course say it is a social democracy. I can distinguish between the two. However, when I say culturally Marxist, what I mean is social democracy as an ideology in which the primary aspects derive from Marxism, like equal rights for both genders... This kind of rhetoric is in many ways a kind of management and ruling technique I may apply, depending on the situation. For those on the left wing this technique is known and used when they stigmatize people as living by a doctrine in which reality is essentially evil. Moreover, we use it on those on the left wing...”

"Are you aware of the 7 questions I asked the other two psychiatrists?” 
FP-2: "No, but you may pose them".

$A B B$ : "It is impossible, in such a huge and important case like 22 July, not to become emotionally overwhelmed by the facts. Except for a few minor events, it is the first terrorist attack of such dimensions. The psychiatric society has no experience with politically motivated violence. Not including politically motivated violent persons as a topic in plans for psychiatric studies results in the major problem that psychiatrists don't know how militant nationalists think, how militant Islamists think, or for that matter, how militant Marxists think. This thinking represents an isolated world which I believe only a minority of psychiatrists, if any at all, are familiar with. It is an unknown and strange world and there are no experts in this field. You are not taught about it in school either. I don't know if you have had the opportunity to study it more profoundly, perhaps you can enlighten me?”

FP-2: "No, not in this field. We follow what happens with the same interest as we would do in any other circumstances. It is not a specific part of our profession. We have a mandate to relate to, where the questions regarding insanity or not, level of consciousness and level of mental impairment are the essentials".

$A B B$ says later that: "It is important that you don't underestimate the knowledge about the mentality of especially Al Qaeda or other Islamic militants. These militants have been sources of inspiration for both me and those few individuals I have associated with".

FP-2's interpretation of DVD (sound only) interview of the terrorist made at Utøya on the afternoon and evening of 22 July 2011.

In their approach to the 22 July interview, FP-2 [7] chose to display large sequences from what the terrorist de facto said after having been apprehended at Utøya. Furthermore, they included the description of additional sounds recorded and their interpretation of what they heard.

The first interview by the police was performed in a house at Utøya immediately after apprehension and continued the same evening and the following night. In the background one could hear the noise from the helicopters transporting the wounded off the island. After having listened to the recordings, FP-2 described [7] that they were left with a somewhat strange and peculiar impression. They noted that at a time when 69 dead persons were still on the island and the nation was paralyzed, ABB was sitting down managing to conduct an almost jovial and sociable conversation. He was friendly and polite answering questions, paying close attention not to compromise third parties. He gave the impression of being somewhat agitated. In some sequences, ABB talked about his political point of view in a larger context in which he also played a role. His explanations were rich in detail and also included some details about his preparations for the terror acts. At a certain point, a situation occurred in which the police expressed a strong desire for information about potential fellow terrorists capable of new strikes. ABB on his side focused more on his demands to have access to a computer to offer to collaborate.

He confirmed that he was responsible for the bombing in Oslo and for the killings at Utøya, but showed no signs of emotion in that regard. ABB's statements about fearing for his own life were understandable in view of the fact that during the apprehension, the police were very close to firing shots directly at him, but did not.

\subsection{The Remaining Police Interviews Evaluated by FP-2 [7]}

FP-2 was appointed after FP-1 had finished their report [4]. The police's interrogations of ABB continued after the report from FP-1 [4]. FP-2 therefore had more interviews to evaluate than FP-1. Regarding the interviews that were evaluated by both teams of psychiatrists, instead of presenting a summary of their interpretations as FP-1 did [4], FP-2 [7] chose to display exact sequences from the police's interrogations.

FP-2 describes ABB's politeness, his initial agitation followed by a calmer period, as did their colleagues [7]. FP-2 underline that they never observed any signs of sadness or signs of regrets during the interviews made available [7]. ABB is described as being cooperative and giving detailed information as long as it did not involve others negatively. In this case, others are those persons who ABB called mentors and fellow founding members of Knights Templar.

FP-2 state that ABB's explanations may in part be judged as being unnecessarily detailed, and furthermore, that he was easily caught by momentary digressions, but also that he was equally easy to get back on track [7].

During some of the interviews FP-2 noticed that ABB, when presenting his global political view and why his terror acts were necessary, had constructed a high and grandiose role for himself. Another observation made was that each time ABB tried to negotiate, he appeared self conscious and demanding.

FP-2 describe [7] how in the interviews made during the police's reconstruction, ABB explained in detail and 
without any signs of emotional engagement what he did on Utøya. These descriptions are more or less identical to FP-1's version [4]. On the other hand, FP-2's comments [7] based on the same background material give little, if any support to FP-1's conclusion [4] of "moderate associative disturbances".

\subsection{Personality Disorders}

In their report, FP-2 [7] state that the terrorist displays symptoms of NPD. This condition is classified in ICD 10 [2] as among those in category F 60.8. FP-2 also felt that the symptoms found when examining the terrorist justified a diagnosis of F 60.2 Dissocial personality disorder. In their diagnostic evaluation, FP-2 uses DSM-IV [13] SCID II in the context of the ICD 10 diagnosis. This is not without problems and will be discussed later. FP-1 [4] made no mention of personality disorders in their report.

To fulfil the ICD 10 criteria [2] for specific personality disorders, a number of general criteria must first be met. Table 1 lists the ICD 10 criteria for personality disorders.

ICD 10 does not specifically define the characteristics of NPD; it is classified as belonging to the category F 60.8 "Other specific personality disorders". The following criteria must be met for the diagnosis F 60.8 [NPD]: "A personality disorder that fits none of the specific rubrics F 60.0 - F 60.7".

DSM-IV-TR (301.81) - The Diagnostic and Statistical Manual of Mental Disorders fourth edition-Text Revised, DSM-IV-TR, defines NPD as shown in Table 2 and classifies it among the dramatic and emotional subtypes (Cluster B).

FP-2 adopted the DSM-IV diagnostic criteria [13] and in the following text taken from their report, symptoms from the examination of the terrorist have been tested against the various criteria for classification of the DSM-IV axis II disorders:

Avoidant personality disorder-ABB gives the impression of being unafraid, engaged and secure in social situations and he is self-confident, but FP-2 found that ABB is vulnerable to criticism and that he is easily offended. In recent years, he had had very few intimate relationships and has a defensive approach regarding intimate relations. According to FP-2, these evaluations rule out avoidant personality disorder.

Dependant personality disorder - The fact that ABB has managed to take care of himself despite living at his mother's house for longer periods, his self-proclaimed one-man terror cell, being the leader of an anti-Islamic organisation, and finally his planning and execution of the terror acts without involving others, does not support a diagnosis of dependent personality disorder.

Obsessive personality disorder-ABB focuses on details, structures, and how to organize his life. This makes him capable of living a life in which he carries through his intentions. His perfectionism may also reach a point at which it becomes a challenge to complete what he initially planned. Still, this did not influence his business, leisure activities, writing, planning, bomb construction, or other activities. His choice of way of life enabled him to focus on different topics at the same time at the cost of spare time for interaction with friends. ABB prefers to do things himself. He has been careful with spending money and he is rigid and perhaps also stubborn, but he is

\section{Table 1. ICD 10 criteria for personality disorders F 60.}

Evidence that the individual's characteristic and enduring patterns of inner experience and behaviour deviate markedly as a whole from the culturally expected and accepted range (or "norm").

Such deviation must be manifest in more than one of the following areas:

G1 1-Cognition (i.e. ways of perceiving and interpreting things, people and events; forming attitudes and images of self and others); 2-Affectivity (range, intensity and appropriateness of emotional arousal and response);

3-Control over impulses and need gratification;

4-Relating to others and manner of handling interpersonal situations.

The deviation must manifest itself pervasively as behaviour that is inflexible, maladaptive, or otherwise dysfunctional across a broad range of personal and social situations (i.e. not being limited to one specific "triggering” stimulus or situation).

There is personal distress, or adverse impact on the social environment, or both, clearly attributable to the behaviour referred to under G2.

G4 There must be evidence that the deviation is stable and of long duration, having its onset in late childhood or adolescence.

G5 The deviation cannot be explained as a manifestation or consequence of other adult mental disorders, although episodic or chronic conditions from sections F 0 to F 7 of this classification may co-exist, or be superimposed on it.

G6 Organic brain disease, injury, or dysfunction must be excluded as possible cause of the deviation (if such organic causation is demonstrable, use category F 07). 
Table 2. DSM-IV-TR criteria for Narcissistic Personality Disorder.

A pervasive pattern of grandiosity (in fantasy or behaviour), need for admiration, and lack of empathy, beginning by early adulthood and present in a variety of contexts, as indicated by five (or more) of the following:

1. Has a grandiose sense of self-importance (e.g., exaggerates achievements and talents, expects to be recognized as superior without commensurate achievements).

2. Is preoccupied with fantasies of unlimited success, power, brilliance, beauty, or ideal love.

3. Believes that he or she is "special" and unique and can only be understood by, or should associate with, other special or high-status people (or institutions).

4. Requires excessive admiration.

5. Has a sense of entitlement, i.e. unreasonable expectations of especially favourable treatment or automatic compliance with his or her expectations.

6. Is interpersonally exploitative, i.e. takes advantage of others to achieve his or her own ends.

7. Lacks empathy: is unwilling to recognize or identify with the feelings and needs of others.

8. Is often envious of others or believes others are envious of him or her.

9. Shows arrogant, haughty behaviour or attitudes.

It is also a requirement of DSM-IV that a diagnosis of any specific personality disorder also satisfies a set of general personality disorder criteria.

not a collector of items. Some traits of obsessive personality disorder may be present and may consequently influence the total score on the Obsessive Personality Disorder Scale, but FP-2 found no support for this diagnosis.

Paranoid personality disorder-FP-2 concluded that there was no reason to suspect paranoid psychosis based on what they had learned and observed. Regarding his friends, ABB revealed no irrational thinking about their loyalty. FP-2 also concluded that ABB's caution and reluctance in sharing information about his terror plans with others seems realistic and should not in this case be considered as irrational. Other elements like the fact that he often perceives peoples' comments as threatening and offensive may give an SCID II score close to the threshold on this item. FP-2 found that ABB had a score of 3 for 2 of the 7 SCID II items for paranoid personality disorder.

Schizotypal personality disorder - is a condition closely related to psychotic disorders. FP-2 found it necessary to thoroughly examine ABB's behaviour in this regard since FP-1 had concluded that he was suffering from F 20.0 paranoid schizophrenia. ABB's behaviour may in some cases be classified as sufficient for sub-threshold scores, e.g. he had had thoughts about having observed surveillance cars with special antennas outside the farm he rented. On returning to the same farm, he had once found an open door and concluded that it had been opened by others. ABB has never displayed any signs of having had strange perceptions or thoughts about magic and there were no signs of superstition or transference of thoughts. FP-2 noted that ABB has a tendency not to let up when discussing his political views, but otherwise not. FP-2 concluded that everything concerning ABB's political ideas and expression should be considered as being part of belonging to a politically extreme subculture.

Schizoid personality disorder-FP-2 found nothing that would suggest that ABB suffers from schizoid personality disorder.

Histrionic personality disorder-FP-2 found nothing that would suggest that ABB suffers from histrionic personality disorder despite the fact that he seems to greatly enjoy other peoples' attention. The latter is rather a narcissistic trait.

Narcissistic personality disorder-ABB read the first forensic psychiatric report and was most likely influenced by it. He concluded that he is narcissistic, although within a range of behaviour that he considers normal. Having reviewed all information made available to them, FP-2 found that ABB has the following narcissistic traits:

1) ABB displays a grandiose ideation regarding his own importance, even if he sometimes tries to moderate this. The grandiosity is especially evident in his manifesto and in describing his role in Knights Templar. The criterion was met.

2) ABB had had ideas about his own success and power many years before the terror acts. This became evident during the psychiatrists' interviews with him and can also be found when reading the manifesto. The desire 
for fame seems to be a strong motivation for ABB in general. The criterion was met.

3) ABB enjoys talking about how he finds it especially motivating to socialize with intelligent persons with a similar high status. He underlines his lack of interest in those who, in his eyes, are of less importance. The criterion was met.

4) ABB is convinced that what he has done is for others to admire, thereby confirming a strong need for admiration. This becomes evident when he is allowed to talk about his political ideology and his terror acts. The criterion was met.

5) The terror acts of 22 July 2011 show that ABB considers he has the right to overrule society's rules and regulations. His reluctance to listen to and discuss other peoples' views may, in retrospect, be associated with his former business activities where he, at times, operated outside the law. The criterion was met.

6) FP-2 found that ABB had made a conscious and strategic choice when he decided to move back to his mother's apartment and remain there for as long as he did. Despite his statements of having had to pay a certain rent, the element of exploitation is recognizable, as is the convenience. The criterion was not fully met.

7) In his own view, ABB is an empathic person. As reference for his ability to recognize and relate to other persons' loss he used his foreseen and accepted loss of family after having performing the terror acts. There were no signs of empathy, remorse or any other emotional signs indicating distress in his statements after the terror acts. This became evident during the reconstructions made on the island of Utøya and later in court. Not showing empathy he explained is due to his ability to de-emotionalize himself. The criterion was met.

8) None of the psychiatrists found signs of envy. ABB has accepted that his friends have made careers, some having well paid jobs. Commenting on his own unsuccessful career, ABB said that he chose to pursue a certain path being well aware of the consequences. The criterion was not met.

9) ABB is clearly arrogant in his behaviour. His arrogance shows itself in many ways e.g., he always insists on being the one with the correct answer. He claims to have read a lot and has no problems with demanding recognition for his hours of reading. To him, his efforts are at least on the level of a university degree. ABB has shown that when other persons' opinions don't fit into his world of ideas, he sets all contradictions aside. The criterion was met.

FP-2 found that 7 of the 9 DSM-IV criteria for SCID II Narcissistic Personality Disorder were met, whereas 5 would have been sufficient for the ICD 10 diagnosis F 60.8 Other specific personality disorders, narcissistic. Furthermore, FP-2 found no symptoms confirming emotional instability. On the contrary, ABB seemed remarkably stable without any emotional aberrations. In this regard, there is unconfirmed information saying that $\mathrm{ABB}$ is quite unstable emotionally outside the court room or under observation.

FP-2 also concluded that ABB fulfilled the criteria for the diagnosis of APD. They chose to apply the DSM term antisocial instead of the ICD term dissocial, although these 2 diagnostic systems, to some degree, differ regarding the classification of antisocial behaviour. Based on SCID II for Antisocial Personality Disorder, FP-2 argued that since ABB had no behaviour indicating disturbances before the age of 13 years, the DSM-IV diagnostic criteria were not met. Applying the ICD 10 criteria, they found that the diagnosis F 60.2 Dissocial Personality Disorder was met.

\subsection{The Combination of DSM-IV and ICD 10 for Personality Disorders}

FP-2 [7] do not explain why they chose to test ABB's personality characteristics against the DSM-IV SCID II criteria and at the same time refer to an ICD 10 diagnosis. It most likely derives from the fact that the criteria for ICD 10 F 60.2 Dissocial Personality Disorder have never been translated into Norwegian. In addition, there is a tradition of using DSM-IV SCID II to confirm suspected, less specific ICD 10 diagnoses, e.g. those clustered under F 60.8 as "Other specific personality disorders". The rationale for FP-2's choice [7] could also be the assumption that the 2 diagnostic systems overlap and that minor differences are irrelevant. In the past, several papers have highlighted the incompatibility issue between the DSM and the ICD diagnostic systems. One study [14] found that when comparing the DSM-III-R to the ICD 10,60\% of the variance in the personality disorder diagnosis represented variance not attributable to the patients. Furthermore, it has also been reported that research results from different studies employing different instruments are not comparable [14]. Another study [15] found that only $29 \%$ of the subjects received the same primary diagnosis in each of the 2 systems, an observation perhaps related to the fact that the ICD 10 has a lower diagnostic threshold than the DSM-IV. A study [16] concluded that the sources of disagreement between the latest versions of the 2 systems could be traced to dif- 
ferences in the conceptualization of some of the personality disorders, and differences between the criteria and the diagnostic thresholds. Other papers have also criticized the use of DSM- or ICD-based clinical interviews for the assessment of personality disorders [17]-[19]. In a study on DSM-IV [13] and ICD 10 [2] diagnosis, the least concordant pair of personality disorders was antisocial [DSM-IV] and dissocial [ICD 10] [2]. In view of this and because psychiatric diagnosis are descriptive and have no hard endpoints, the strength of the diagnosis $\mathrm{F} 60.8$ remains a matter for discussion.

\subsection{Paranoid Schizophrenia}

Paranoid schizophrenia has a central role in this paper since FP-1 concluded that ABB suffers from this according to ICD 10. Table 3 presents the ICD 10 criteria for schizophrenia and the DSM-IV criteria have been added in order to make comparisons. The paranoid type features delusions or auditory hallucinations. Symptoms like thought disorder, disorganized behaviour or affective flattening are not present in this subtype of schizophrenia. Delusions are persecutory and can be of grandiose nature. Finally jealousy, religiosity, and somatisation may also be present. The APA DSM-V psychosis work group has recommended eliminating the subtypes of schizophrenia contained in the DSM-IV ("Paranoid Type", "Disorganized Type", "Catatonic Type", "Undifferentiated Type", and "Residual Type") and subsuming all of these subcategories under one diagnosis, "Schizophrenia".

\subsection{Severe Psychopathology or Classification of Abnormal Behaviour}

There are several hypotheses that explain the link between severe psychopathology and personality disorder, none being mutually exclusive [20]. As for schizophrenia, we have learned that patients with this disorder lack emotional and hedonic capacity and are prone to experience negative affect. Furthermore, those who develop schizophrenia have abnormal premorbid personalities [20].

Studying the impact of specific personality traits on symptomatology, disability and outcomes in schizophrenia, it was found that higher extraversion was associated with fewer positive and negative symptoms and less subjective distress. Higher neuroticism was associated with more positive symptoms, more severe delusions and greater distress, whereas psychoticism had no effect on symptomatology [21]. A general profile of high psychoticism, low agreeableness, low conscientiousness and low openness has been shown to represent stable personality characteristics over time, suggesting that they are not due to acute state effects [22]. Based on research, of which selected findings have been referred to above, personality traits seem strongly related to the most common mental illnesses. However, how these traits more specifically relate to psychopathology is less clear.

In the report by FP-1 on ABB [4], there were no indications as to the rationale behind their choice of interpretation of the behaviour observed. Nor was there any discussion regarding whether their classification of

Table 3. ICD 10 and DSM-IV diagnostic criteria for schizophrenia.

\begin{tabular}{|c|c|}
\hline \multicolumn{2}{|c|}{ Characteristic symptoms } \\
\hline ICD 10 & DSM-IV \\
\hline \multicolumn{2}{|c|}{ At least one of } \\
\hline $\begin{array}{c}\text { Thought echo, thought insertion/withdrawal/broadcast } \\
\text { Passivity, delusional perception } \\
\text { Third person auditory hallucination, running commentary } \\
\text { Persistent bizarre delusions }\end{array}$ & $\begin{array}{l}\text { Bizarre delusions } \\
\text { Third person auditory hallucinations } \\
\text { Running commentary }\end{array}$ \\
\hline \multicolumn{2}{|c|}{ Or two or more of } \\
\hline $\begin{array}{l}\text { Persistent hallucinations } \\
\text { Thought disorder } \\
\text { Catatonic behaviour } \\
\text { Negative symptoms } \\
\text { Significant behaviour change }\end{array}$ & $\begin{array}{c}\text { Delusions } \\
\text { Hallucinations } \\
\text { Disorganized speech } \\
\text { Grossly disorganized behaviour } \\
\text { Negative symptoms }\end{array}$ \\
\hline \multicolumn{2}{|c|}{ Duration } \\
\hline More than 1 month & $\begin{array}{c}1 \text { month of characteristic symptoms } \\
\text { With } 6 \text { months of social/occupational dysfunction }\end{array}$ \\
\hline
\end{tabular}


symptoms should be considered within the frames of personality disorders or psychopathology. FP-1 thought ABB had grandiose delusions regarding his own role in an extremist universe. He was considered delusional, having bizarre and paranoid qualities that went beyond conspiracy notions about an Islamist take-over of Europe [3].

\section{Discussion}

\subsection{Childhood and Developmental Issues_Lack of Identity}

Growing up with a mentally unstable mother as the only caregiver may have influenced the development of ABB's identity. A psychologist recommending foster care for ABB as a 3 - 4 years old child described the child's lack of ability to play and to interact socially. There were obvious psychosocial problems in the family and the father took the mother to court with a custody claim. After the father left, the mother had several lovers and $\mathrm{ABB}$ became attached to some. Repeated loss of potential father figures may therefore also have influenced ABB's development as a child.

Following the various testimonies given during the court proceedings, the impression which remains is that ABB's lack of identity gradually surfaced as he grew up. Although a bit blurred around the edges, a picture in which ABB had tried to find a place to fit in since adolescence, both socially and professionally, became much clearer. Seeking a fortune without any parental guidance or mentorship, ABB dropped out of high school, presumably because he felt he could do better without formal education. ABB has a history of having started several businesses, sometimes operating outside the law. At one point, he joined a right wing political organization and tried to make himself a political career, but failed to do so. He also failed to establish relationships on which he could build his own family. He joined the freemasons but rarely participated in meetings. ABB adopted extreme political views beyond the established conservative branches in Norwegian society, thereby excluding himself from the company of potential ideological companions. He ended up as an eccentric, almost bankrupt, moving back in with his mother where he stayed in his room playing computer games for hours and days at the time.

\subsection{The Creation of an Identity}

The idea of Knights Templar may have been something he picked up reading the history of the masonry. Certainly, some of the terms he later used in his manifesto bear some resemblance to the terms used to describe orders and ranks among the freemasons.

Regardless of whether a terror organisation named Knights Templar exists or not, ABB's belief in such an organisation, even on a fantasy level, underlines his need for something to refer and relate to. Previous research on terrorists has concluded that a common denominator seems to be the need for group identification in order to strengthen one's personal identity and at the same time to reduce one's own and one's group's responsibility [23].

There are many ways to interpret ABB's use of steroids and other performance enhancing substances. Likewise, the cosmetic surgery performed on his nose. One way to consider it is in the context of building and creating an identity as an adult.

\subsection{Performance Enhancing Substances}

Between 25 April and 15 June 2011, ABB used methandrostenalone $40 \mathrm{mg}$ [4 × $10 \mathrm{mg}$ tablets] daily. From 15 June to 22 July, he used $50 \mathrm{mg}$ stanozolol daily. For 2 - 3 days before 22 July he used a mixture of ephedrine, caffeine and aspirin [Ekastac]. Blood samples taken on 23 July 01:37 and at 01:51 showed the following blood levels: efedrine $0.2 \mathrm{mmol} / \mathrm{L}$, coffeine $19.3 \mathrm{mmol} / \mathrm{L}$, cotinine $1.3 \mathrm{mmol} / \mathrm{L}$. Efedrine and metabolites of stanozolol were found in urine samples. Clinical examination at the time of the blood sampling revealed nothing remarkable except for psychological stress [7]. Due to allergies, ABB had also taken an antihistamine called loratadine for approximately 2 weeks before the terror attacks. Based on the results from blood and urine analysis, there were no indications that ABB was under strong influence of drugs on 22 July.

\subsection{The Terrorist's Behaviour-Interviews-Court Room Appearances}

During the court proceedings, ABB openly admitted that he had adapted his statements in accordance with 
FP-1's conclusion [4]. Thus, FP-2 had different conditions under which to conduct their investigations and evaluations. ABB did not consider himself to be a psychiatric patient and he used every opportunity to repeat his monologue about his political views and aims, emphasizing that his fight was for Norway and Europe aiming to save us all from islamisation. Every morning, at the start of the trial when entering the courtroom, ABB consequently raised his right arm in a salute not unlike the German Nazi salute. When he spoke, ABB made it clear that his aim was to spread his message to as many people as possible. He tried several times but once it became evident what he was going to talk about, he was stopped by the presiding judge. ABB frequently spoke to his lawyers and passed them written notes. He sometimes smiled to those present in the courtroom, and during the testimonies from the survivors and other victims, ABB sometimes looked right at them. He had made it clear that he had no choice regarding what he had done and had no regrets.

Following questions from the victims' lawyers and sometimes from the prosecutors, ABB at times had problems with giving precise answers and he was especially vulnerable regarding his use of historical facts to support his political views.

As the days went by, ABB got more and more used to appearing in court. At the beginning, he answered difficult questions with "I don't remember" and "I don't know", but at a later stage, changed the subject and talked about his "mission". ABB got visibly upset and emotional only once, when he cried during the presentation of a montage of some of his propaganda photos accompanied by music. Once he was asked if he felt anything when witnessing people crying during their appearance in court. He answered that he had to lock everything out in order to avoid emotional reactions. Other times he answered aggressively, especially following questions from the prosecution. With few exceptions, ABB seemed unaffected by what was presented during the long trial.

\subsection{The Risk of Under-Interpretation and Over-Interpretation-Differential Diagnosis}

Browsing the literature it is hard to find studies on subgroups of assassins. A publication from 1982 [24] refers to a study of presidential assassins in the United States where 4 types of murderers with different personality characteristics are identified. Some are driven by personal interest; some are anxious and dysphoric and in need of acceptance and recognition. Others are emotionless psychopaths and some are suffering from mental disorders [24]. As for classification of ABB, accepting the court's decision and thereby ruling out serious mental disorders like schizophrenia is one important step. Perhaps an excessive focus on mental illness has made it difficult to accept an individual's right to make free and coherent choices even if it means breaking the law. This right is recognized in modern societies as being closely linked to the ability of assuming the responsibility for one's actions accepting the verdict. Regardless of personality, total devotion to a cause or fanaticism may be the motive behind terror acts like those seen in Norway on 22 July 2011. We may provide psychological models for understanding, but we must avoid always looking to psychiatry in our desperate need for an explanation for something we dislike or don't understand.

\subsection{Being Prepared to Die in a Terror Act versus Suicide-Different Motivation?}

According to Joiner [25], there are two elements which must be present in order for suicidal behaviour to occur: The desire for suicide may have two components: thwarted belongingness and perceived burdensomeness. The first is a sense of social alienation or a failure to form social bonds, while perceived burdensomeness is the sense that one is a burden on persons in their lives. Together, these two elements create the motivational force for the suicidal behaviour. Gunn et al. [26] conclude after having studied 261 suicide notes from 1091 consecutive suicides that Joiner's theory of suicide may apply to only a small percentage of those leaving suicide notes. Joiner [25] used suicide notes to provide supportive evidence for the theory.

In the past, several events have been frequently found to precede suicidal behaviour, i.e. loss events, disrupted interpersonal relationships, job problems and financial difficulties, and events related to physical health [27]. Whether or not the impact of less negative events should be considered as value-neutral or even as positive, remains inconclusive.

Brym and Araj [28] question the assumption that suicide bombers are motivated by an unusually high prevalence of depression and suicidal tendencies as advocated by Merari et al. [29] [30]. The authors conclude that there is reason to question the value of a psychological approach to the study of suicide bombers. They base their points of view on interviews with immediate family members and close friends of Palestinian suicide bombers. They underline the importance of focusing on the political and social roots of the suicide bomber phe- 
nomenon.

There is no information about ABB leaving a suicide note. He may have had brief depressive episodes earlier in his life, but there is no information to support that he was severely depressed at the time of performing the terror acts. ABB explained in court that the night before the terror acts, he spent the night at his mother's. After breakfast he started his preparations. He drove the van with the bomb to the government building area. A few meters before he reached the final destination, he made a brief stop reflecting on having reached the point of no return. What seemed to be the motivation was allegedly his political conviction that he was the only person capable of performing the necessary terror acts. ABB later explained in court that when he was about to ignite the fuse which would initiate the sequence leading to explosion, he noticed that volatile gas was leaking from the $950 \mathrm{~kg}$ fertilizer bomb material. This scared him since the risk of an immediate explosion after lighting the fuse. Despite this, he convinced himself to go through with ignition.

When apprehended on the island of Utøya, ABB later explained in court that he chose to lay down his weapons when he was addressed by the armed special forces and this despite earlier claiming that he did not expect to survive. Once arrested, he was afraid that the police would torture and kill him. ABB later explained that during his reflections and thoughts about his imminent death, he felt sorry for his family and friends.

\section{Author's Comments}

Looking back at what we know about the life of ABB, there are factors contributing to difficulties for ABB to create an identity as an independent individual with sufficient self-esteem. Such factors are e.g. being raised by a mentally ill mother, where borders regarding physical contact and sexuality are unclear, thereby causing sexual ambivalence and identity problems. Likewise, living with a mother who constantly devaluates his father may contribute to identity problems. Especially when the mother several times introduced new men to whom ABB got attached before she broke up the relationship. ABB at some point took a role as his mother's caretaker and as an adult he once said to one of his friends that it would have been better if he had been raised by his father, referring to his life with a mother who most likely had been overprotective. As an adult he tried to establish something for himself and made drastic decisions regarding his own future e.g. abandoning school, starting enterprises based on criminal activity like selling false identity papers. All just to fail and move back to his mother's apartment, avoiding contact with successful friends and playing World of Warcraft for days at the time. His attempts to become someone in politics also failed as he lacked the necessary ability to compromise and was regarded as too extreme in his views. His lack of girlfriends despite bragging about their existence to friends who knew better, must also have undermined his self-esteem. Consequently, there is reason to assume that there was a lack of identity in ABB; a lack for which he had to compensate.

ABB explained in court that he understood that his actions were atrocious but underlined their necessity. He also stated during the court proceedings that the future will prove him right and that his actions would later be understood. He also expressed that he saw himself as the one who had to choose between lesser evils and that he was the only one capable of making such a choice at the time. Despite being contradicted by the victims' lawyers, he maintained that he was an empathic person. Such statements have signs of both a self-heroic view and a need for admiration.

During his testimony and explanations ABB was interrupted several times by the judge when he deliberately used his given time to talk about his future political and violent aims. Regardless of the judge's repeated corrections, ABB continued his critical political propaganda. This lack of respect for the court was confirmed by his statement where he clearly expressed that he did not acknowledge the court since it was appointed by the dominant party in the Norwegian government at the time. Persons from the public present in the court room reacted in different ways to what the terrorist said, one time a shoe was thrown, barely missing the terrorist's head. This made him smile back at them.

At some point, ABB created his imaginary kingdom where he was the saviour, thereby maintaining his selfdeception of being successful. Could ABB's rage be ascribed, at least in part, to the fact that our society failed to recognize his narcissistic needs?

In court, we learned that $\mathrm{ABB}$ had submitted newspaper articles but they were refused, thereby supporting his notion that no one would listen. ABB has confirmed that in his view our society in general is dominated by the left wing; the politicians and the media using all means, including corruption if necessary, to suppress the voices of right wing dissidents. Identifying strongly with the latter group, ABB may have felt like a desperate victim. It 
is also tempting to speculate that $\mathrm{ABB}$, before planning the terror attacks, perceived society as being ungrateful when refusing him credit for what he was trying to convey. Therefore, one way to look at ABB is through the eyes of a desperate and frustrated man without identity, sufficient social and moral ballast, and with a great need of acknowledgement for his ideas. There may be a need to speak up and protest against what is perceived as lack of respect, and thoughts about punishment may be conceived. All depending on the choices available, to someafter diplomacy, only one road is left open: the use of force. There is a strong impression that ABB had a great need to make a difference. In retrospect perhaps also a need for a life commitment—even something worth dying for? The killings make the element of punishment evident, but there is also the element of self-pity. The latter is found in ABB's description of when he, during his execution of the children, first took aim on a victim and then lowered his gun when he saw a terrified young man that reminded him of himself.

Paranoid schizophrenia, antisocial/dissocial personality disorder and NPD were the 3 diagnoses discussed in the two forensic reports. Expert witnesses testifying in court argued strongly against the diagnosis of paranoid schizophrenia, first of all because the ICD 10 general criteria for schizophrenia were not met. But there were also those who argued that ABB had sufficient symptoms to match the requirements for the DSM-IV diagnosis [3]. Eventually, NPD and traits of APD were chosen as the final diagnosis. Little attention was paid to these classifications since they had no relevance to the court's decision on whether or not ABB might be insane and unaccountable for his actions. Likewise, it had no relevance for his competence to stand trial.

In any classification and categorization of more or less identical signs there will always be diagnostic overlap in the hands of health professionals. The use of specific categorical criteria may yield minor differences. For signs to become symptoms, a choice has to be made. Mental health professionals differ regarding which signs they eventually classify as symptoms.

Diagnostic systems may vary a great deal, up to sevenfold—in their rates of diagnosing schizophrenia [31]. The currently used diagnostic procedures are associated with a number of assumptions [32] [33] and there are notable problems linked to facts, like different disorders existing within the schizophrenia construct. The dimensional nature of a construct makes it difficult to relate to categorical definitions within the same construct [33].

A study applying a modified and expanded version of the Manual for the Assessment of Schizophrenia [MAS] [34] [35] on 660 psychotic patients introduced the term "general schizophrenia factor". This refers to shared factors within the various diagnostic systems based on common symptoms like delusions, formal thought disturbances, hallucinations, and some types of negative symptoms [33]. A study by Landmark et al. [34] emphasizes the fact that schizophrenia-related variables show continuous distribution which in turn makes cut-offs between schizophrenic and non-schizophrenic psychosis arbitrary. Skeptics [33] have expressed that: "A dimensional construct is consistent with the interpretation that traditional diagnostic systems are the result of both drawing artificial boundaries on a dimensional construct and emphasizing [or de-emphasizing] different phenomenological and clinical aspects of the construct”.

A comparison between the degrees of relationship following application of criteria-based diagnosis-specifically for schizotypal, borderline, avoidant and obsessive-compulsive personality disorders, demonstrated [36] that the choice of assessment methodology may have influenced the clinicians' ratings with consequences for the consistency and intercorrelation measures. Still it was found that these 4 personality disorder subtypes were more interrelated with each other than with the remaining personality diagnoses [36]. A study following patients with borderline personality disorder (BPD) concluded that among those with persistent BPD there is more comorbidity with other personality disorders than in those in whom the BPD had remitted [37].

NPD is not a separate personality disorder in ICD 10, but it is recognized as a specific entity by the DSM diagnostic system. Critics have suggested that pathological narcissism should be described as a range of personality pathology common to several personality disorders, alternatively as a severity dimension, ranging from normal assertiveness to pathological narcissism [38] [39]. As for the validity of the DSM-IV construct, a study has suggested that NPD taxonomic structure might not be a spurious outcome due to the raters' biased expectations, but that, as a whole, it can be defended to maintain NPD as a separate diagnostic category in the DSM nomenclature [40]. With reference to the diagnoses given by the 2 pairs of forensic psychiatrists in the ABB case; i.e. paranoid schizophrenia and NPD, many have searched for a plausible explanation behind the different conclusions, including internal weaknesses in the two diagnostic systems used. The diagnosis of paranoid schizophrenia was based on the ICD 10 diagnostic system [2], whereas NPD was based on the DSM-IV [13].

Studying the literature and making the assumption that a diagnosis of schizophrenia in ABB was based on observation of brief prodromal signs that disappeared later, one study caught my attention [41]. Studying the 
symptoms in 29 patients with prodromal schizophrenia, 48\% qualified for one or more current axis I diagnoses, including cannabis dependence, major depressive disorder and alcohol dependence. Interestingly, $48 \%$ of the prodromal patients also qualified for an axis II disorder, most commonly schizotypal, followed by BPD. Of special interest was that among the $48 \%$ prodromal schizophrenics with concurrent axis II diagnoses, none had NPD, 17\% had BPD and 7\% had APD [41]. A study of 461 patients with personality disorder investigated how impulsive and aggressive traits related to individual Cluster B personality disorders [42]. It was found that the most frequently diagnosed personality disorder (16.1\%) was NPD and that emotional components of aggression such as anger and irritability were prominent features. Interestingly, this is in contrast to what was found in patients with APD in whom instrumental aggression [i.e. physical aggressiveness] is prominent. Consequently, and in accordance with the findings presented [43], patients with NPD were described as quick tempered and in favor of activities without strict rules and regulations. The narcissistic patients were likely to lose control and become aggressive when their irritation increased because of low frustration tolerance [43]. Of interest was also the observation that patients with passive-aggressive personality disorder were similar to those with NPD regarding the propensity to lose their temper [43]. However, in contrast to patients with NPD, the passive-aggressive patients had a hostile and malevolent view of other people [41]. From the descriptions of ABB found in the forensic reports, it is evident that many of the signs observed would fit the description of specific narcissistic personality traits.

\section{Comorbidity between Schizophrenia and Personality Disorders}

Literature on comorbidity between psychiatric disorders and personality disorders and especially the more chronic symptom disorders reveal that specific personality disorders are often found [44]. In a recent study on comorbid ICD 10 personality traits in schizophrenia, $65.1 \%$ of patients with schizophrenia had a comorbid personality disorder, compared to $19 \%$ of the healthy general population. This high comorbidity rate will have a significant impact on the clinical and cognitive characteristics of schizophrenia [45], a conclusion in line with results from earlier studies emphasizing that co-occurrence of independent psychiatric disorders affects phenomenology, course and treatment [46]. According to studies using standardized research instruments [DSM-III], at least 50\% of subjects with a personality disorder have two or more co-existing personality disorders [47]-[50].

The research done on Cluster B personality disorders and schizophrenia has mainly focused on comorbid APD and BPD. One study found that only antisocial personality disorder is significantly associated with premeditated aggression in schizophrenia, whereas the other disorders in Cluster B are not [51].

In the case of $A B B$, some of the signs reported and interpreted as symptoms of paranoid schizophrenia by FP-1 might overlap with symptoms associated with BPD. In fact, the latter diagnosis was one of those also discussed by FP-2. Looking at the comorbidity between schizophrenia and BPD, a study found that about $18 \%$ of 142 individuals with diagnosed schizophrenia had comorbid BPD [52]. The patients with both diagnoses showed less improvement in psychiatric symptoms under treatment, particularly for hostility and suspiciousness, but also for global functioning. They were also re-hospitalized more often than the schizophrenia patients without BPD. Co-occurrence of schizophrenia and BPD is therefore not infrequent, and BPD has a significant negative longitudinal impact on the course and outcome in schizophrenia patients [52].

Accordingly, assuming that ABB indeed is suffering from schizophrenia, a comorbid personality disorder would most likely lower his level of functioning and attenuate the intensity of his hostility and suspiciousness. With few exceptions, evidence of such attenuation was clearly not apparent in court. A few times his responses had an aggressive tone. His facial expression, with just a subtle smile, rarely changed, except when he cried during the documentation of his self-made propaganda video. When he responded to comments on his lack of empathy he claimed that he had to protect himself from his own feelings to maintain emotional control.

ABB refused to acknowledge what he considered imposed symptoms of paranoid schizophrenia. Thus, only the investigator's interpretations of signs observed and historical descriptions remained. Even though there were several months between the 2 observations, the fact that such completely different diagnostic conclusions were reached has unsettled many colleagues. Moving from descriptions and observations of phenomena to signs and eventually symptoms is a process subject to many different influences, of which experience and personal choice of the investigators are perhaps the major fasctors. No inter-rater estimates were incorporated into the two reports on the mental health of ABB presented during the court proceedings.

The court's decision of ABB being mentally sane is based on the principle of giving the defendant the benefit 
of the doubt. The two forensic psychiatric reports were contradictive in their conclusions and essential for the court to answer was the question of whether there was an imminent risk that ABB could commit new atrocities in case he were set free. ABB said several times in court that he had not finished his work, referring to his terror acts. The court was left with no option but to rule against him due to the established imminent threat. In Norway the court has to decide between a time limited and a time non-limited sentence. The non-limited sentences are two; a sentence to psychiatric treatment for the mentally insane and preventive detention for those found mentally sane. In this case on August $24^{\text {th }} 2012$, ABB was sentenced to 21 years of preventive detention with a minimum of 10 years to be served before he would be entitled to appeal the court's decision. If he after 10 years demands to have his case reopened, the court must once more answer the question of whether there is an imminent risk for new atrocities or not. If yes, the court will have to prolong the sentence.

\section{References}

[1] Stormark, K. (2011) Da terroren rammet Norge. 189 minutter som rystet verden. Kagge Forlag, Oslo.

[2] World Health Organisation (1992) ICD 10 Classifications of Mental and Behavioural Disorder: Clinical Descriptions and Diagnostic Guidelines. World Health Organisation, Geneva.

[3] Melle, I. (2013) The Breivik Case and What Psychiatrists Can Learn from It. World Psychiatry, 12, 16-21. http://dx.doi.org/10.1002/wps.20002

[4] (2011) First Forensic Psychiatric Report. https://sites.google.com/site/breivikarkiv/dokumenter/anders-behring-breivik-rettspsykiatrisk-erklaering-2011-11-29

[5] Mergård, M. (2012) Voldsom, lunefull og full av uventede innfall. Newspaper Article Aftenposten 14.06. http://www.aftenposten.no/nyheter/iriks/22juli/--Voldsom_-lunefull-og-full-av-uventede-innfall-6850270.html

[6] Vikås, M., Brenna, J.G., Nygaard, F. and Hopperstad, M. (2011) Psykolog i 1983: Ideelt sett burde han vært i et stabilt fosterhjem. Newspaper Article VG nett 23.12.

http://www.vg.no/nyheter/innenriks/terrorangrepet-22-juli-anders-behring-breivik/psykolog-i-1983-ideelt-sett-burde-ha n-vaert-i-et-stabilt-fosterhjem/a/10024865/

[7] (2012) Second Forensic Psychiatric Report. http://www.nrk.no/norge/hadde-treningskamerat-fra-midtosten-1.7724579

[8] Borchgrevink, A.S. (2012) En norsk tragedie (A Norwegian Tragedy). Gyldendal, Oslo.

[9] Karterud, S., Wilberg, T. and Urnes, Ø. (2010) Personlighetspsykiatri (Personality in Psychiatry). Gyldendal, Oslo, 63.

[10] Skille, Ø.B. and Bålsrød, K. (2011) En av treningskameratene på ungdomsskolen var jo fra Midtøsten. Interview, National Norwegian Broadcasting 23.07.2011.

https://sites.google.com/site/breivikarkiv/dokumenter/anders-behring-breivik-rettspsykiatrisk-erklaering-2012-04-10

[11] Meland, A. (2011) Dette mislyktes Anders Behring Breivik med. Dagbladet (Norwegian Newspaper), 04.09., 6. www.Dagbladet.no

[12] Dagbladet (Norwegian Newspaper) (2011) Skrøt av egen briljans, utseende, kjærester og penger. http://www.dagbladet.no/2011/07/27/nyheter/utoya/massedrap/innenriks/17459033/

[13] American Psychiatric Association (2000) Diagnostic and Statistical Manual of Mental Disorders. 4th Edition, Text Rev., Arlington.

[14] Bronisch, T. and Mombour, W. (1994) Comparison of a Diagnostic Checklist with a Structured Interview for the Assessment of DSM-III-R and ICD 10 Personality Disorders. Psychopathology, 27, 312-320. http://dx.doi.org/10.1159/000284889

[15] Sara, G., Raven, P. and Mann, A. (1996) A Comparison of DSM-III-R and ICD 10 Personality Disorder Criteria in an Out-Patients Population. Psychological Medicine, 26, 151-160. http://dx.doi.org/10.1017/S0033291700033791

[16] Starcevic, V., Bogojevic, G. and Kelin, K. (1997) Diagnostic Agreement between the DSM-IV and ICD 10 DCR Personality Disorders. Psychopathology, 30, 328-334. http://dx.doi.org/10.1159/000285078

[17] Ottosen, H., Ekselius, L., Grann, M. and Kullgren, G. (2002) Cross-System Concordance of Personality Disorder Diagnosis of DSM-IV and Diagnostic Criteria for Research of ICD 10. Journal of Personality Disorders, 16, $283-292$. http://dx.doi.org/10.1521/pedi.16.3.283.22537

[18] Beltran, R.O., Silove, D. and Llewellyn, G.M. (2009) Comparison of ICD 10 Diagnostic Guidelines and Research Criteria for Enduring Personality Change after Catastrophic Experiences. Psychopathology, 42, 113-118. http://dx.doi.org/10.1159/000204761

[19] Frances, A.J. and Widiger, T. (2012) Psychiatric Diagnosis: Lessons from the DSM-IV Past and Cautions for the DSM-5 Future. Annual Review of Clinical Psychology, 8, 109-130. 
http://dx.doi.org/10.1146/annurev-clinpsy-032511-143102

[20] Andersen, A.M. and Bienvenu, O.J. (2011) Personality and Psychopathology. International Review of Psychiatry, 23, 234-247. http://dx.doi.org/10.3109/09540261.2011.588692

[21] Lysaker, P.H. and Davis, L.W. (2004) Social Function in Schizophrenia and Schizoaffective Disorder: Associations with Personality, Symptoms and Neurocognition. Health and Quality of Life Outcomes, 2, 15.

[22] Kentros, M., Smith, T.E., Hull, J., McKee, M., Terkelsen, K. and Capalbo, C. (1997) Stability of Personality Traits in Schizophrenia and Schizoaffective Disorder: A Pilot Project. Journal of Nervous and Mental Disease, 185, 549-555. http://dx.doi.org/10.1097/00005053-199709000-00003

[23] Stauber, E. (2001) Ethnopolitical and Other Group Violence: Origins and Prevention. In: Chirot, D. and Seligman, M.E.P., Eds., Ethnopolitical Warfare: Causes, Consequences, and Possible Solutions, American Psychological Association, Washington DC, 290-304.

[24] Clarke, J.W. (1982) American Assassins: The Darker Side of Politics. Princeton University Press, Princeton.

[25] Joiner Jr., T.E. (2005) Why People Die by Suicide. Harvard University Press, Cambridge.

[26] Gunn III, J.F., Lester, D., Haines, J. and Williams, C.L. (2012) Thwarted Belongingness and Perceived Burdensomeness in Suicide Notes. Crisis, 33, 178-181. http://dx.doi.org/10.1027/0227-5910/a000123

[27] Yen, S., Pagano, M.E., Shea, M.T., Grilo, C.M., Gunderson, J.G., Skodol, A.E., McGlashan, T.H., Sanisow, C.A., Bender, D.S. and Zanarini, M.C. (2005) Recent Life Events Preceding Suicide Attempts in a Personality Disorder Sample: Findings from the Collaborative Longitudinal Personality Disorder Study. Journal of Consulting and Clinical Psychology, 73, 99-105. http://dx.doi.org/10.1037/0022-006X.73.1.99

[28] Brym, R.J. and Araj, B. (2012) Are Suicide Bombers Suicidal? Studies in Conflict \& Terrorism, 35, 432-443. http://dx.doi.org/10.1080/1057610X.2012.675550

[29] Merari, A., Diamant, I., Bibi, A., Broshi, Y. and Zakin, G. (2010) Personality Characteristics of "Self Martyrs”/“Suicide Bombers" and Organizers of Suicide Attacks. Terrorism and Political Violence, 22, 87-101. http://dx.doi.org/10.1080/09546550903409312

[30] Merari, A. (2010) Driven to Death. Oxford University Press, Oxford.

[31] Endicott, J., Nee, J., Fleiss, J.L., Cohn, J., Williams, J.B.W. and Simon, R. (1982) Diagnostic Criteria for Schizophrenia. Reliabilities and Agreement between Systems. JAMA Psychiatry, 39, 884-889. http://dx.doi.org/10.1001/archpsyc.1982.04290080006002

[32] Berner, P., Gabriel, E., Katsching, H., Kieffer, W., Koehler, K., Lenz, G., Nutzinger, D., Schanda, H. and Simhandl, V. (1992) Diagnostic Criteria for Functional Psychosis. Cambridge University Press, Cambridge. http://dx.doi.org/10.1017/CBO9780511663208

[33] Peralta, V. and Cuesta, M.J. (2005) The Underlying Structure of Diagnostic Systems of Schizophrenia: A Comprehensive Polydiagnostic Approach. Schizophrenia Research, 79, 217-229. http://dx.doi.org/10.1016/j.schres.2005.05.003

[34] Landmark, J. (1982) A Manual for the Assessment of Schizophrenia. Acta Psychiatrica Scandinavica, 65, 1-85.

[35] Peralta, V. and Cuesta, M.J. (1992) A Polydiagnostic Approach to Self-Perceived Cognitive Disorders in Schizophrenia. Psychopathology, 25, 232-238. http://dx.doi.org/10.1159/000284778

[36] Grilo, C.M., McGlashan, T.H., Morey, L.C., Gunderson, J.G., Skodol, A.E., Tracie, S.M., Sanislow, C.A., et al. (2001) Internal Consistency, Intercriterion Overlap and Diagnostic Efficiency of Criteria Sets for DSM-IV Schizotypal, Borderline, Avoidant and Obsessive-Compulsive Personality Disorders. Acta Psychiatrica Scandinavica, 104, $264-272$. http://dx.doi.org/10.1034/j.1600-0447.2001.00436.x

[37] Links, P.S., Heslegrave, R. and van Reekum, R. (1998) Prospective Follow-Up Study of Borderline Personality Disorder: Prognosis, Prediction of Outcome and Axis II Comorbidity. Canadian Journal of Psychiatry, 43, 265-270.

[38] Emmons, R.A. (1987) Narcissism: Theory and Measurement. Journal of Personality and Social Psychology, 52, 11-17. http://dx.doi.org/10.1037/0022-3514.52.1.11

[39] Morey, L.C. and Jones, J.K. (1998) Empirical Studies on the Construct Validity of Narcissistic Personality Disorder. In: Roningham, E., Ed., Disorder of Narcissism: Diagnostic, Clinical and Empirical Implications, American Psychiatric Press, Washington DC, 351-373.

[40] Fossati, A., Beauchaine, T.P., Grazioli, F., Carretta, I., Cortinovis, F. and Maffei, C. (2005) A Latent Structure of Diagnostic and Statistical Manual of Mental Disorders, Fourth Edition, Narcissistic Personality Disorder Criteria. Comprehensive Psychiatry, 46, 361-367. http://dx.doi.org/10.1016/j.comppsych.2004.11.006

[41] Rosen, J.L., Miller, T.J., D’Andrea, J.T., McGlashan, T.H. and Woods, S.W. (2006) Comorbid Diagnoses in Patients Meeting Criteria for the Schizophrenia Prodrome. Schizophrenia Research, 85, 124-131. http://dx.doi.org/10.1016/j.schres.2006.03.034 
[42] Fossati, A., Barratt, E.S., Borroni, S., Villa, D., Grazioli, F. and Maffei, C. (2007) Impulsivity, Aggressiveness, and DSM-IV Personality Disorders. Psychiatry Research, 149, 157-167. http://dx.doi.org/10.1016/j.psychres.2006.03.011

[43] Baumeister, R.F., Bushman, B.J. and Campbell, W.K. (2000) Self-Esteem, Narcissism and Aggression: Does Violence Result from Low Self-Esteem or from Threatened Egoism? Current Directions in Psychological Science, 9, 26-29. http://dx.doi.org/10.1111/1467-8721.00053

[44] Alnaes, R. and Torgersen, S. (1988) The Relationship between DSM-III Symptom Disorders (Axis I) and Personality Disorders (Axis II) in an Outpatients Population. Acta Psychiatrica Scandinavica, 78, 485-492. http://dx.doi.org/10.1111/j.1600-0447.1988.tb06371.x

[45] Moore, E.A., Green, M.J. and Carr, V.J. (2012) Comorbid Personality Traits in Schizophrenia: Prevalence and Clinical Characteristics. Journal of Psychiatric Research, 46, 353-359. http://dx.doi.org/10.1016/j.jpsychires.2011.11.012

[46] Tyrer, P., Gunderson, J., Lyons, M. and Tohen, M. (1997) Extent of Comorbidity between Mental State and Personality Disorders. Journal of Personality Disorders, 11, 242-259. http://dx.doi.org/10.1521/pedi.1997.11.3.242

[47] Pfohl, B., Coryell, W., Zimmerman, M. and Stangl, D. (2006) DSM-III Personality Disorders: Diagnostic Overlap and Internal Consistency of Individual DSM-III Criteria. Comprehensive Psychiatry, 27, 21-34. http://dx.doi.org/10.1016/0010-440X(86)90066-0

[48] Loranger, A.W., Susman, V.L., Oldham, J.M. and Russakoff, M. (1987) The Personality Disorder Examination: A Preliminary Report. Journal of Personality Disorders, 1, 1-13. http://dx.doi.org/10.1521/pedi.1987.1.1.1

[49] Oldham, J.M., Skodol, A.E., Kellman, H.D., Hyler, S.E., Rosnick, L. and Davies, M. (1992) Diagnosis of DSM III R Personality Disorders by Two Structured Interviews: Patterns of Comorbidity. American Journal of Psychiatry, 149, 213-220.

[50] Cold, J. (2013) The Co-Morbidity of Personality Disorder and Lifetime Clinical Syndromes in Dangerous Offenders. The Journal of Forensic Psychiatry and Psychology, 14, 341-366.

[51] Bo, S., Forth, A., Kongerslev, M., Haahr, U.H., Pedersen, L. and Simonsen, E. (2013) Subtypes of Aggression in Patients with Schizophrenia: The Role of Personality Disorders. Criminal Behaviour and Mental Health, 23, 124-137. http://dx.doi.org/10.1002/cbm.1858

[52] Bahorik, A.L. and Eack, S.M. (2010) Examining the Course and Outcome of Individuals Diagnosed with Schizophrenia and Comorbid Borderline Personality Disorder. Schizophrenia Research, 124, 29-35.

http://dx.doi.org/10.1016/j.schres.2010.09.005 
Scientific Research Publishing (SCIRP) is one of the largest Open Access journal publishers. It is currently publishing more than 200 open access, online, peer-reviewed journals covering a wide range of academic disciplines. SCIRP serves the worldwide academic communities and contributes to the progress and application of science with its publication.

Other selected journals from SCIRP are listed as below. Submit your manuscript to us via either submit@scirp.org or Online Submission Portal.
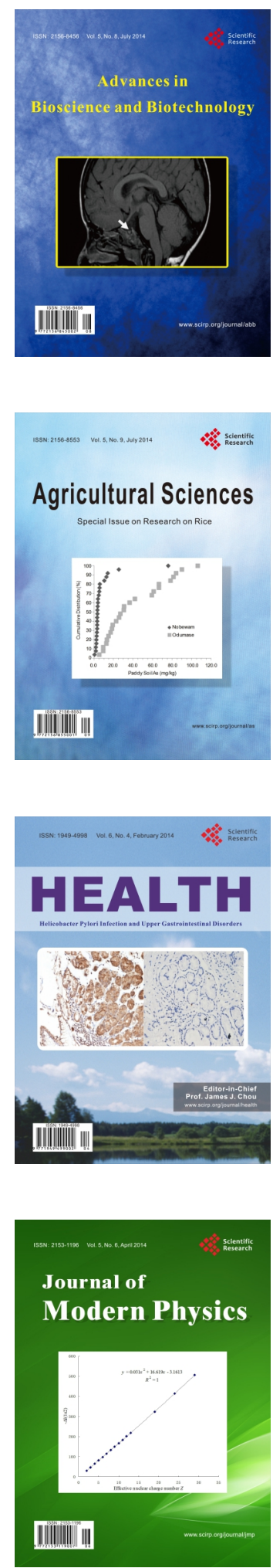
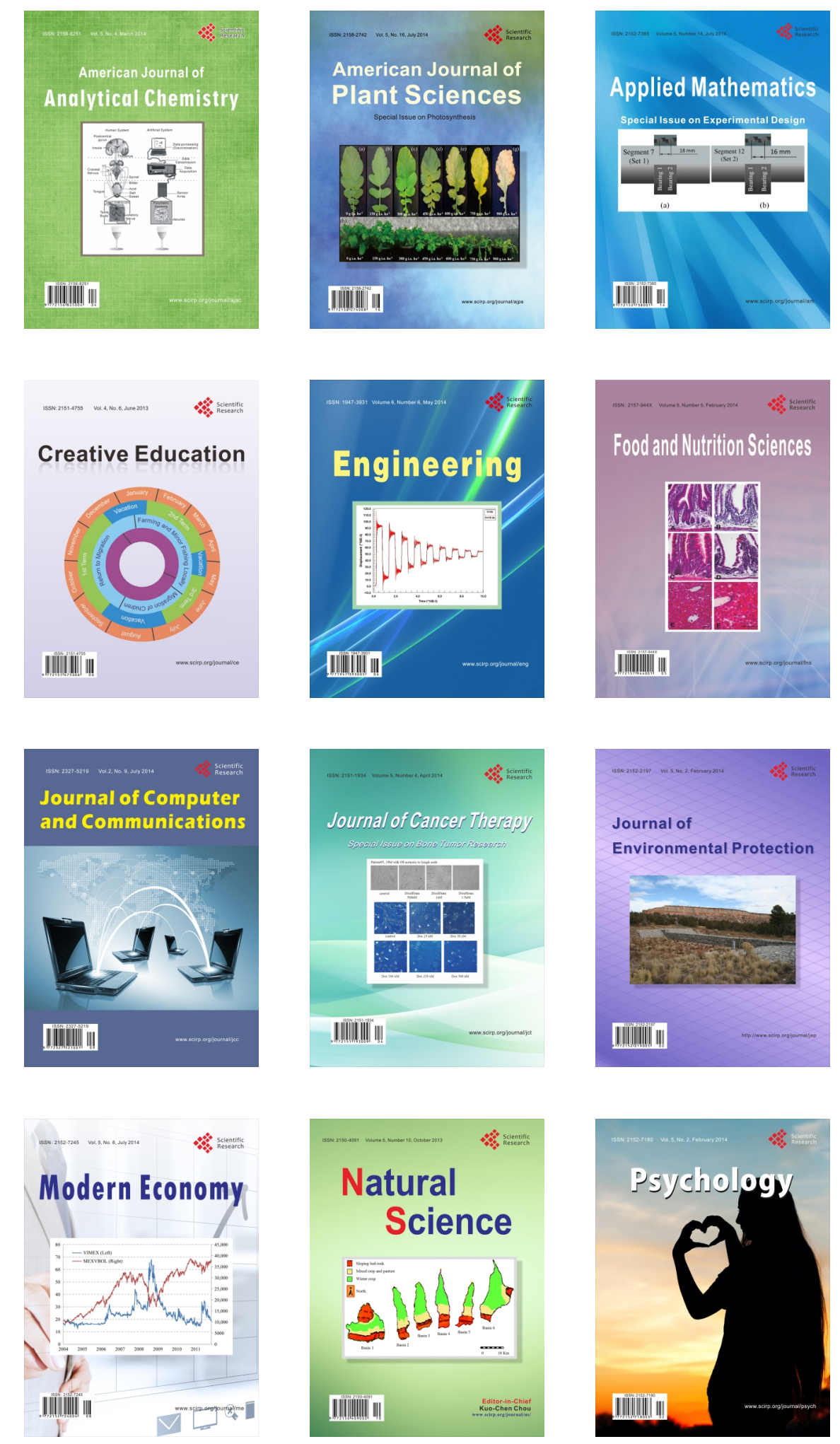